\title{
Gangliocytic paraganglioma of the duodenum
}

\author{
Filip Čečka $M D P h D^{1}$, Bohumil Jon $M D P h D^{1}$, Rudolf Repák $\mathrm{MD}^{2}$, \\ Aleš Kohout MD PhD ${ }^{3}$, Zdeněk Šubrt MD PhD ${ }^{1}$, Alexander Ferko MD PhD ${ }^{1}$
}

\begin{abstract}
A
54-year-old woman was examined following a positive fecal occult blood test performed within the screening program for colorectal cancer. The patient had no symptoms, no previous surgeries and her history was unremarkable. Physical examination and basic laboratory tests, including a blood count, were normal. A coloscopy was performed with a finding of a single polyp $5 \mathrm{~mm}$ in size in the sigmoid colon. The polyp was removed endoscopically and the histological examination revealed an adenoma. Subsequently, gastroduodenoscopy was performed and revealed a duodenal lesion very near the ampulla (Figure 1). The lesion was $18 \mathrm{~mm}$ in diameter with ulceration at the apex. No bleeding was visible. A biopsy sample was taken from the ulceration. No malignant structures were found. Endosonography was then performed and showed the homogeneous structure of the lesion originating from the submucous layer of duodenum. No lymphadenopathy was found (Figure 2). Magnetic resonance imaging revealed a mass in the second portion of the duodenum with no significant lymphadenopathy and no distant metastases.

The diagnosis was not known before the treatment, but the lesions had the hallmark characteristics of a gastrointestinal stromal tumour. Endoscopic treatment of the lesion was considered but was not possible due to its location; thus, surgical resection was pursued. The abdominal cavity was approached through a right subcostal incision. A
\end{abstract}

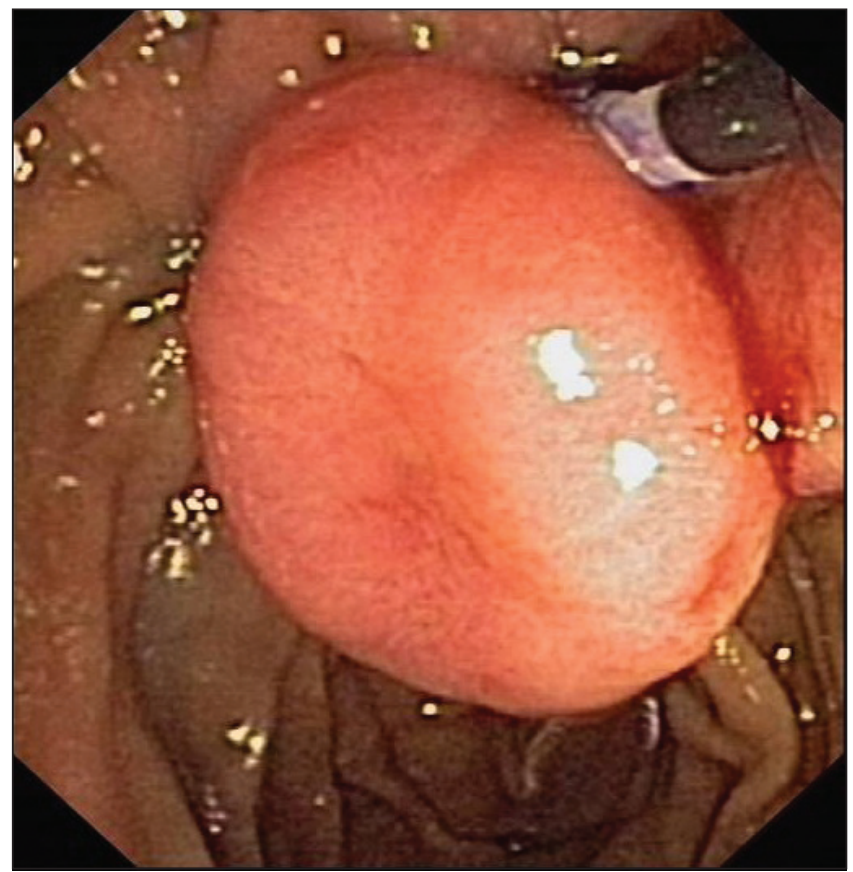

Figure 1) Gastroduodenoscopy showing a mass in the duodenum duodenotomy in the D2 was performed along with extirpation of the lesion. No complications occurred. The postoperative course was uneventful and the patient was discharged on postoperative day 11. A final histological examination showed findings typical of gangliocytic paraganglioma of the duodenum (Figure 3); the resection line was free of the tumour.

The patient is currently being followed-up at our department and is complaint free, showing no signs of recurrence of the disease twoand-a-half years after the surgery.

\section{DISCUSSION}

Gangliocytic paraganglioma was first described by Dahl in 1957 (1). It is an extremely rare gastrointestinal tumour that is found predominantly in the second part of the duodenum, although some authors reported cases invading the proximal jejunum $(2,3)$. There is a slight male predominance. The age at presentation ranges from 15 to 80 years, with an average of 54 years (4).

The pathogenesis of this tumour is unclear. It has been suggested that the lesion is due to hamartomatous proliferation of endodermal cells at the ventral primordium of the pancreas and neuroectodermally derived ganglion and Schwann cells $(3,5)$. This would help explain the high incidence of the tumour in the second portion of duodenum.

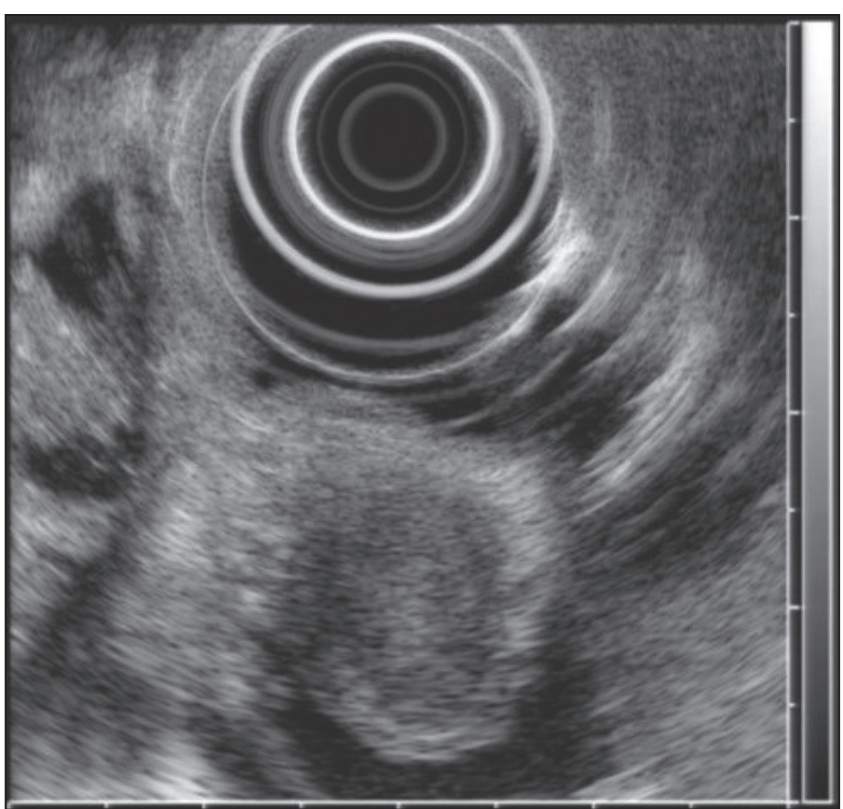

Figure 2) Endosonography showing homogenous lesion $15 \mathrm{~mm}$ in diameter, it does not infiltrate muscularis propria. There is no lymphadenopathy

${ }^{1}$ Department of Surgery; ${ }^{2}$ Department of Gastroenterology; ${ }^{3}$ Department of Pathology, Medical Faculty and University Hospital Hradec Králové, Czech Republic

Correspondence: Dr Filip Čečka, Department of Surgery, University Hospital Hradec Králové, Sokolská 581, Hradec Králové, Czech Republic.

Telephone 42-0-49-583-3570, fax 42-0-49-583-2026, e-mail filip.cecka@seznam.cz

Received for publication July 6, 2012. Accepted July 12, 2012 
Histologically, the tumour shows triphasic cellular differentiation with the presence of epitheloid neuroendocrine cells, spindle-shaped cells with Schwannian features and ganglion cells. The relative abundance of these cell types may vary $(2,5)$. Precise diagnosis is verifiable by immunohistochemistry. In the described case, the neuroendocrine cells were positive for keratins, synaptophysin and chromogranin. Both mentioned neuroendocrine markers also labelled ganglion cells. Spindle cells showed strong expression of S-100 protein. CD117 was positive only focally in ganglion cells. The immunohistochemical profile of the reported tumour was consistent with other reports $(2,5)$.

The most common presenting symptoms are abdominal pain, upper gastrointestinal bleeding and, less frequently, biliary obstruction or duodenal obstruction. Otherwise, these tumours are found incidentally during radiological imaging or during endoscopy performed for different purposes (2-4). Ultrasound shows a solid isoechogenic mass. On computed tomography scan and magnetic resonance imaging, these tumours are solid and homogenous in appearance (2). Its endoscopic picture does not differ from other submucosal tumours and, therefore, endosonography with biopsy is usually advocated (2). However, accurate preoperative diagnosis is often difficult.

Small tumours are managed with local excision performed endoscopically or surgically by means of duodenotomy. Larger tumours with lymph node involvement require pancreaticoduodenectomy with standard lymph node dissection (2,3). No adjuvant treatment strategy has been determined due to the rarity of the disease (3).

Although these tumours are usually benign, several cases of lymph node metastasis and even distant metastases have been reported $(3,5)$. Recurrence does not usually occur after radical resection. No cases of death resulting from gangliocytic paragangliomas have been reported. However, continuous follow-up is recommended for early detection of a recurrence $(2,5)$.

ACKOWLEDGEMENT: Supported by the project (Ministry of Health, Czech Republic) for conceptual development of research organization 00179906.

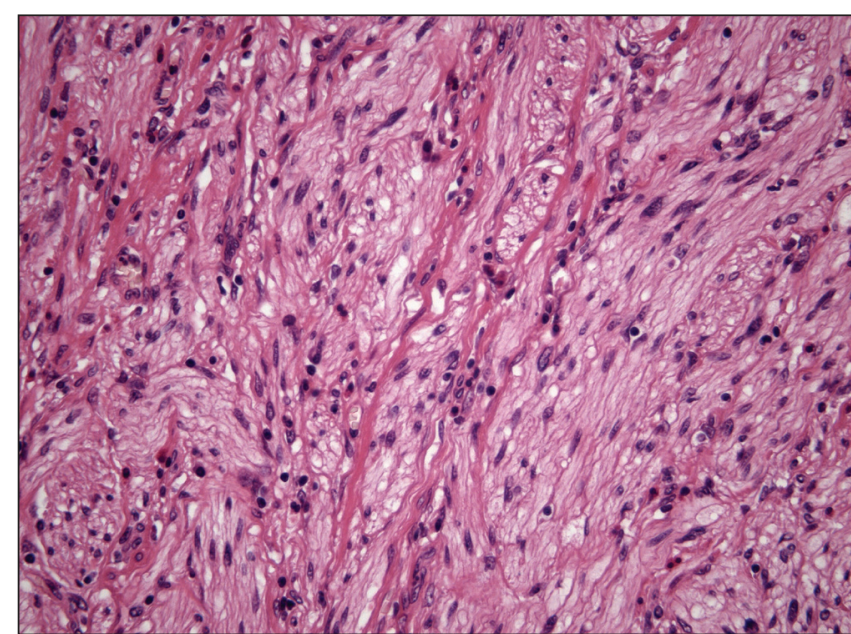

Figure 3) Histological examination of the surgical specimen showing an irregular composition of spindle cells typical of gangliocytic paraganglioma. Hematoxylin-eosin stain, original magnification $\times 40$

\section{REFERENCES}

1. Dahl EV, Waugh JM, Dahlin DC. Gastrointestinal ganglioneuromas; brief review with report of a duodenal ganglioneuroma. Am J Pathol 1957;33:953-65

2. Kwon J, Lee SU, Kang MJ, Jang J-Y, Kim S-W. A case of gangliocytic paraganglioma in the ampulla of Vater. World J Surg Oncol 2010;8:42.

3. Mann CM, Bramhall SR, Buckels JA, Taniere P. An unusual case of duodenal obstruction - gangliocytic paraganglioma. J Hepatobiliary Pancreat Surg 2009;16:562-5.

4. Burke AP, Helwig EB. Gangliocytic paraganglioma. Am J Clin Pathol 1989;92:1-9.

5. Ogata S, Horio T, Sugiura Y, Aiko S, Aida S. Duodenal gangliocytic paraganglioma with regional lymph node metastasis and a glandular component. Pathol Int 2011;61:104-7.

The Canadian Journal of Gastroenterology is now considering a limited number of submissions for IMAGE OF THE MONTH. These are based on endoscopic, histological, radiological and/or patient images, which must be anonymous with no identifying features visible. The patient must consent to publication and the consent must be submitted with the manuscript. All manuscripts should be practical and relevant to clinical practice, and not simply a case report of an esoteric condition. The text should be brief, structured as CASE PRESENTATION and DISCUSSION, and not more than 700 words in length. A maximum of three images can be submitted and the number of references should not exceed five. The submission may be edited by our editorial team.

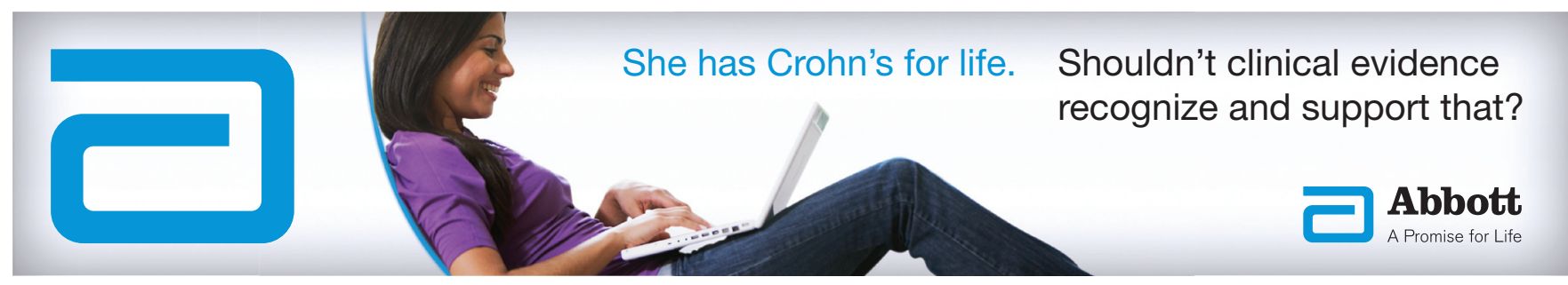




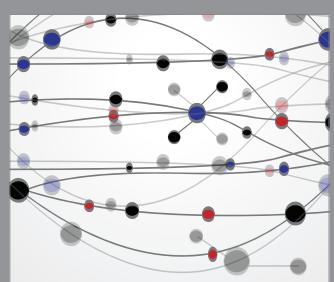

The Scientific World Journal
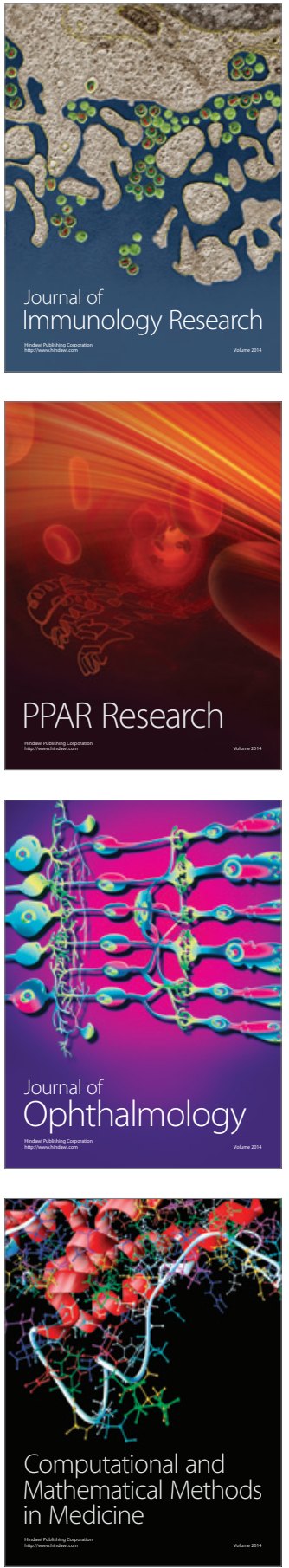

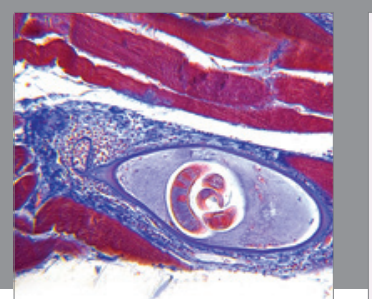

Gastroenterology Research and Practice

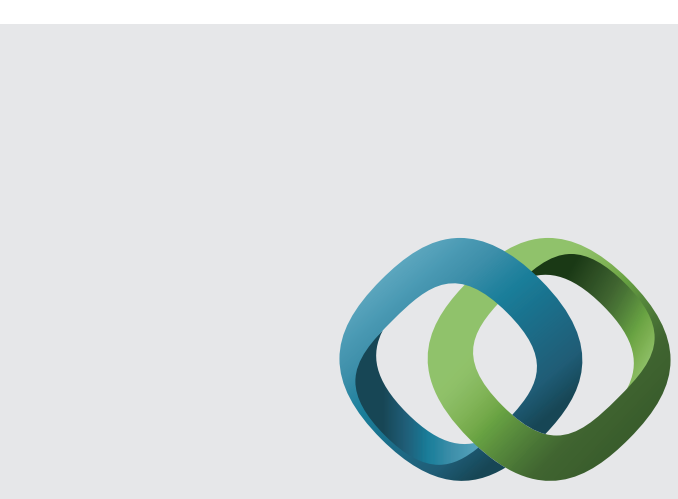

\section{Hindawi}

Submit your manuscripts at

http://www.hindawi.com
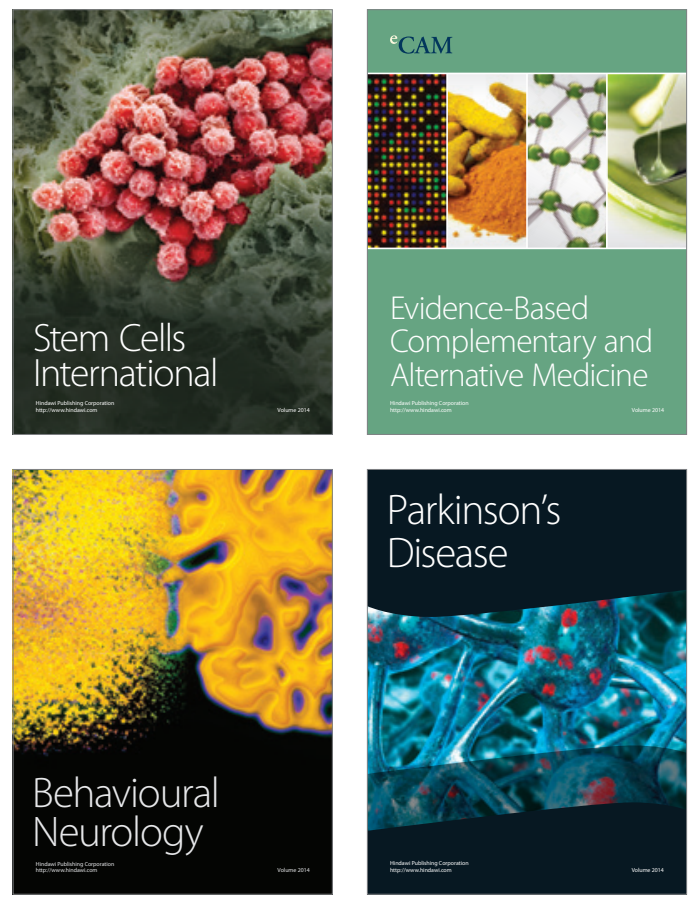
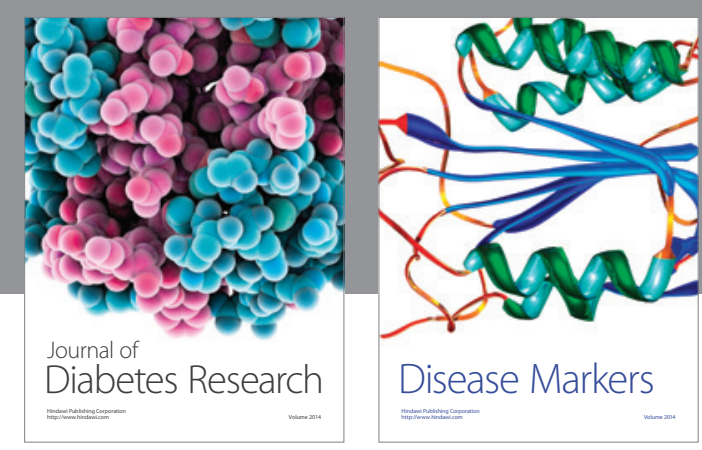

Disease Markers
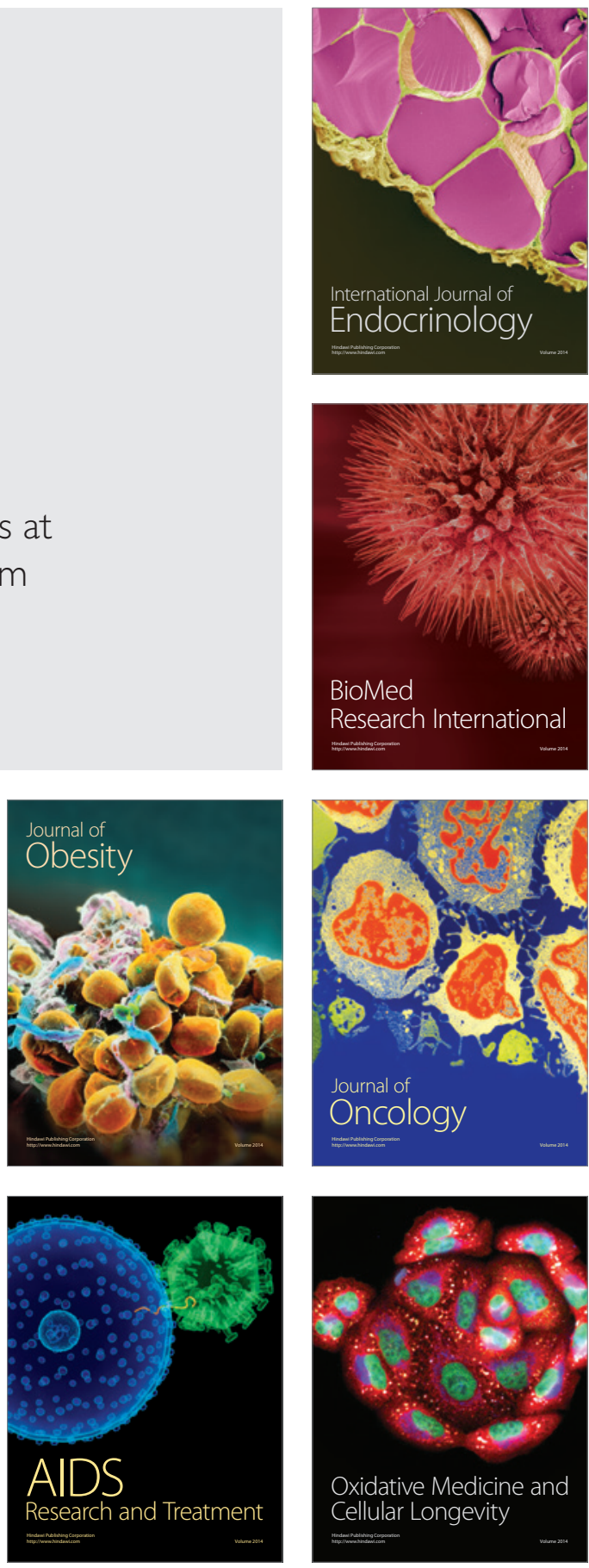